\title{
Does Providing Improved Biomass Cooking Stoves Free-of-Charge Reduce Regular Usage? Do Use Incentives Promote Habits?
}

\author{
Randall Bluffstone \\ Abebe Beyene \\ Zenebe Gebreegziabher \\ Peter Martinsson \\ Alemu Mekonnen \\ Ferdinand M. Vieider
}

\begin{abstract}
This paper uses a field experiment and real-time electronic stove use monitors to evaluate effects of monetary treatments on usage intensity of one of the most important improved biomass-burning cookstoves promoted in Ethiopia. Understanding whether, how much and why improved stoves are used are important, because use frequency critically determines fuelwood savings and related benefits. We find that distributing stoves free-of-charge is at least as effective for promoting shortrun adoption as requiring payments or offering usage incentives. Free distribution is most effective at promoting high and increasing levels of longer-run regular use.
\end{abstract}

Key words: Field Experiment; Improved Stoves; Ethiopia.

JEL code: C93; I12; O12; O13; Q23; Q56. 


\section{Introduction}

Humans have cooked their food for several hundred thousand years (e.g., Wrangham et al. 1999), mainly using biomass fuels. About two-fifths of the human population or 2.8 billion people currently rely on solid cooking fuels, including biomass, combusted in their homes rather than gas, liquid fuels or electricity (e.g., Grieshop et al. 2011; Jeuland et al. 2015b). Biomass fuels are especially widely used in low-income developing countries, such as Ethiopia, which is the focus of this paper, often self-collected and combusted in simple, flexible stoves, such as the three-stone tripod, which is the traditional technology in much of Sub-Saharan Africa. Biomass fuel use is a potential problem, because it contributes to indoor and outdoor air pollution (Smith et al. 2013; Martin et al. 2011; Lim et al. 2010), forest degradation (Gebreegziabher and van Kooten 2013), which can increase fuelwood collection time (Cooke et al. 2008; Amacher et al. 2004; Bluffstone 1995) and increase climate change (Bailis et al. 2015; Saatchi et al. 2011; Bond et al. 2013).

Several large international initiatives, such as Sustainable Energy for All (www.se4all.org), promote modern energy services as an important way to reduce the use of biomass fuels. Fuels such as gas and electricity require major public infrastructure investments, supply chain development and the purchase of often-expensive stoves. Biomass fuels will therefore continue to be extensively used, particularly by people in sub-Saharan Africa, and the number of people that depend on biomass is expected to decline relatively little by 2030 (IEA 2017).

Improved cooking stoves $\left(\mathrm{ICS}^{1}\right)$ that use less biomass have received significant attention as important intermediate technologies while modern fuel availability and adoption expands (Jeuland and Pattanayak 2012). These technologies, most of which burn fuelwood, have the

\footnotetext{
${ }^{1}$ In this paper ICS means improved biomass cooking stoves. We recognize that other types of technologies, such as electric induction and LPG stoves, among others, can represent important improvements.
} 
potential to reduce many of the deleterious effects of biomass burning, ${ }^{2}$ and may require only minor alterations in cooking habits. Many ICS were introduced in the 1980s and accepted into peoples' homes, but often cooks did not regularly use those stoves (e.g., Gil 1987; Barnes et al. 1993). It soon came to be recognized that ICS adoption really has two parts. The first is willingness to try stoves, but the second and more ambitious aspect is regular use, which is the main litmus test of true adoption (Beyene et al. 2015; Hanna et al. 2016; Johnson et al. 2009). For this reason, in this paper we focus on adoption measured as regular use.

We utilize a field experiment to examine short and longer-run usage intensity of a relatively durable, simple, low-maintenance improved biomass stove called Mirt. This stove is an important part of a major Federal Government of Ethiopia effort to disseminate ICS to 20 million households by 2030 (FDRE 2011) and has been shown to use less wood (Gebreegziabher, 2018). We focus on the effect of monetary treatments on regular and sustained use of the Mirt ICS, which can potentially provide important guidance on subsidy policies. We also seek to add to the literature on the effects of monetary incentives on the use of new technologies in developing countries, which to-date has largely focused on explicitly health-related technologies (e.g., see Dupas 2014; Cohen and Dupas 2010; Ashraf et al. 2010; Chassang et al. 2012). Recently, however, the effect of monetary incentives has also been examined with regard to ICS (e.g. see Pattanayak et al. 2016; Usmani et al. 2017; Bensch and Peters 2017; Levine et al. 2018). Our paper provides additional evidence that lessons from this important literature apply to improved biomass cookstoves.

The remainder of the paper proceeds as follows. Section 2 discusses the key literature on

\footnotetext{
${ }^{2} \mathrm{~A}$ particularly interesting development is the potential for improved stoves to reduce greenhouse gas emissions and carbon finance has been used to fund both private sector and nonprofit pay-for-performance stove programs (Lewis and Pattanayak 2012). For example, the firm DelAgua Health has distributed more than 100,000 EcoZoom stoves in Rwanda (http://www.delagua.org/projects/rwanda ). See www.projectsurya.org for an interesting example of a nonprofit project relying on carbon finance.
} 
subsidy policies and adoption, as well as the Mirt ICS. Section 3 presents the design of our field experiment. Section 4 discusses the results and the final section draws key conclusions and policy implications.

\section{Literature}

Evidence on actual, field-based use of ICS in Sub-Saharan Africa is important, because improved biomass cookstove designs promoted in Africa have recently been found to reduce the fuelwood or charcoal needed to cook typical meals by approximately $20 \%$ to $35 \%$ compared with traditional technologies. ${ }^{3}$ A significant portion of this literature either ignores real-world usage (e.g. Gebreegziabher et al. 2018) or uses relatively long-term respondent recall rather than actual measurements (e.g. Dresen et al. 2014; Bensch and Peters 2015; Hanna et al. 2016). As was done by Simons et al. (2017), we avoid using self-reporting, which may have little correlation with actual use (Ramanathan, et al. 2016) and has been shown to lead to use overestimates by as much as $100 \%$ (Thomas et al. 2013; Beltramo and Levine 2013). We directly calculate use frequency with electronic stove use monitors (SUMs) that measure stove surface temperature every 10 minutes for between one and two months.

Recent literature includes careful analyses of usage behaviors, many of which focus on benefits and costs from users' perspectives. Though the literature includes evidence of robust usage and significant benefits (e.g. Bensch and Peters 2015), other research suggests limited usage, which has been explained in terms of limited direct benefits to ICS users (e.g. Hanna et al. 2016)

\footnotetext{
${ }^{3}$ The potential for fuelwood savings can be undercut in important ways by stove-stacking behaviors, in which ICS and traditional technologies are both used (Ruiz-Mercado and Masera 2015; Beltramo and Levine 2013, Brooks et al. 2016; Bensch and Peters 2015). In some cases, these effects are significant enough to offset efficiency gains (e.g. Beltramo and Levine 2013). In other situations, such rebound effects are minor (e.g. Brooks et al. 2016).
} 
or over-emphasis on respiratory health benefits that are not highly valued by users (e.g. Mobarak et al. 2012; Pattanayak and Pfaff 2009).

On the cost side, first-cost has been found to be important for initial adoption. Price elasticities are likely to be high (e.g. Mobarak et al. 2012) and adoption quite low with full-cost pricing even if stoves cost less than $\$ 7.00$ (Bensch et al. 2015). Female-headed households, marginalized groups and the poor may have especially low willingness to pay (e.g. Jeuland et al. 2015a). For this reason, significant subsidies or free distribution are common in large-scale stove programs (e.g. Rosa et al. 2014; Samaddar 2017). Financing has also been found to dramatically increase adoption (Beltramo et al. 2015; Levine et al. 2018); first costs are therefore of critical importance to ICS adoption, which is why we emphasize them in this paper.

Subsidies, such as free distribution, can promote uptake, but they may also have negative effects on efficiency. Subsidies can reduce screening effects, implying that technologies go to those who do not value them and will not use them (e.g., Ashraf et al. 2010; Chassang et al. 2012). Free distribution may also mute psychological sunk cost effects that could promote use. There is a growing literature on how monetary incentives affect use of goods and services as diverse as mosquito nets (Dupas 2014), exercising at gyms (Charness and Gneezy 2009), water treatment tablets (Ashraf et al. 2010) and more recently, ICS (Usmani et al. 2017). Overall, little evidence seems to exist that psychological sunk costs (i.e. payments in the past) promote use (Ashraf et al. 2010; Cohen and Dupas 2010) or that low initial costs reduce long-run values (Bensch and Peters 2017). These findings suggest that subsidized prices may not reduce usage.

Our paper adds to the literature, which seeks to continue to bring ICS into the discussion. Using a difference-in-difference empirical specification applied to our field experiment data, we evaluate the effects of three monetary incentive structures on Mirt ICS use. Mirt costs about 
$\$ 12.00$ (about the same as the stove analyzed by Hanna et al. 2016), is made locally of molded concrete and is one of the most important improved stoves promoted in Ethiopia ${ }^{4}$. This stove is less prone to breakage than others that have been evaluated in the literature (e.g., Hanna et al. 2016), allowing us to focus on the role of monetary incentives in regular and sustained ICS usage.

Mirt is used to make injera, which is the main staple bread consumed in Ethiopia, and in areas without refrigeration is baked at least twice per week (Kindu Trust, undated). Reducing fuelwood to cook injera is important, because it may represent the end-use for as much as half of the primary energy consumed in the country (Bizzarri 2010; Tesfay 2014). Mirt has been estimated to use $50 \%$ less wood in laboratory tests (GIZ 2011), 40\% to 50\% based on surveys (Megen Power 2008; Dresen et al. 2014) and $20 \%$ to $30 \%$ using field-based controlled cooking tests (Gebreegziabher et al. 2018). Very few rural households use ICS (Mondal et al. 2018), with most households relying on tripods made of three large stones that waste approximately $90 \%$ of the energy input ( Alem et al. 2014).

We randomly distribute the Mirt ICS free-of-charge, at a subsidized cost and with a reward for regularly using it during the first monitoring period, which was approximately 6-weeks long. We find that on average Ethiopian households use the Mirt stove approximately twice per week, which in rural areas is consistent with regular injera baking. We also find that the rate of complete dis-use after approximately one year is low at about $10 \%$ and there is limited evidence of reduced average use frequency over time.

Consistent with the literature, we do not find evidence of psychological sunk cost effects,

\footnotetext{
${ }^{4}$ Mirt means "best" in Amharic language. The Mirt stove was initially developed by the Ethiopian Energy Study and Research Center (EESRC), has a lifetime of about 5 years and has been promoted since 1998 by the Federal Government of Ethiopia and the German aid agency GIZ. It is a key part of the government's Climate Resistant Green Economy Strategy (FDRE 2014, 2015). NGOs are also involved and as of 2016 approximately 50,000 Mirt stoves had been distributed by World Vision alone.
} 
and in the short-run free distribution is found to promote regular usage no more or less than requiring payment or subsidizing regular usage. We also find evidence of high and increasing levels of regular use over time when the stove is provided for free.

\section{Field Experiment}

To better understand improved biomass stove use decisions and generate testable hypotheses, we modify the one-period analytical model of Jeuland et al. (2015a). We focus exclusively on contemporaneous use decisions, because in our field experiment all users accepted the stoves (i.e. took, purchased or agreed to an incentive arrangement) regardless of the terms offered. The details of the analytical framework are presented in Appendix A. Results suggest the following main hypotheses, as well as a number of subsidiary hypotheses, which are tested empirically within the context of our randomized field experiment ${ }^{5}$ :

1. Sunk costs do not affect stove use. Stove prices affect usage only via screening effects;

2. Pay-for-use schemes promote higher usage rates compared with the other two monetary treatments only during the incentivized period.

\subsection{Experimental design}

We have three monetary treatments: (i) users receive the stove for free, which is our baseline treatment; (ii) inspired by Cohen and Dupas (2010), users pay 25 Birr for the Mirt stove (about $13 \%$ of the approximately 192 Birr cost) paid the same day or latest the following day ${ }^{6}$, and

\footnotetext{
${ }^{5}$ We thank an anonymous reviewer for calling attention to these subsidiary hypotheses, which we test below.

${ }^{6}$ Mirt stoves are made by private producers, so prices vary. The exchange rate in June 2013 when the Mirt stoves were distributed was approximately 19 Birr/\$US and the daily unskilled wage rate was approximately 40 Birr. The subsidized price reflects benefits from reduced fuelwood consumption, such as carbon sequestration, that accrue to other than stove adopters. This subsidy level is not atypical if stoves are not provided free as in Rosa et al. (2014). For example, in Ethiopia, World Food Program (undated) reports offering an 80\% subsidy, Samaddar (2017) offers an $87 \%$ subsidy in Udaipur, India and Bailis (2018) reports an 80\% subsidy in their liquified petroleum gas RCT in
} 
(iii) users pay nothing for their stoves and receive a 50 Birr incentive payment if the electronic SUM discussed in detail below indicated that Mirt stoves were used at least twice per week during the first approximately six-week monitoring period. We chose twice per week, because it is consistent with regular injera cooking. This treatment follows an experimental approach similar to Charness and Gneezy (2009) and Bensch and Peters (2017) and investigates the longer-run effect of incentivizing use during the first period. ${ }^{7}$

An exclusive focus on the very short-run can lead to erroneous extrapolations about longerrun usage intensity if short-run effects are not persistent, if people need time to become accustomed to interventions to develop habits or both. For this reason, we evaluate effects over an approximately one-year timeframe. ${ }^{8}$

We randomized at the village rather than the household level to assure that everyone in a village received their Mirt stoves on the same terms. This approach best reflects implementation at scale, where all individuals in a site receive stoves under exactly the same conditions. If stoves were allocated using different treatments within a village, this would have been perceived as unfair, potentially biasing usage intensity compared with use based purely on stove attributes and treatments. In sum, treatments are assigned randomly by village and households were randomly selected within each village. Sampling details are discussed in Section 3.3.

\subsection{Measuring Use of the Mirt stove}

India. The price in this treatment precludes analysis of screening effects and reduces potential sunk cost effects compared with higher prices.

${ }^{7}$ Half the sample was randomized into village level groups that received one-time group training. These groups were found to have no effect on usage and are treated as a control in all models, but not analyzed.

${ }^{8}$ See Alcott and Rogers (2014) on electricity use, Hanna et al. (2016) for improved stoves and Frey and Rogers (2014) for an overview. 
We monitor all stoves over four intervals lasting between one and two months for more than one year. In contrast to some of the literature (e.g. Hanna et al. 2016), we identify cooking events by electronically measuring surface temperature. For this purpose, we use DS1922T SUMs, which were purchased from Berkeley Air Monitoring Group of Berkeley, California and, as shown in Figure 1 in Appendix B, are approximately the size of a watch battery. The recording intervals on the SUMs are adjustable and we recorded temperatures every ten minutes for up to 60 days. The DS1922T can tolerate temperatures up to 120 degrees Celsius.

Respondents were shown the SUMs, which were placed on stoves using heat resistant tape. They were told that the devices record the temperature of the stove, and in the future enumerators would come to their houses to download the data. Field workers also informed respondents about necessary safety measures. Though Simons et al. (2017) argue that such sensors can reduce Hawthorne effects compared with other alternatives, we acknowledge the possibility of behavioral responses to the monitors that differ by treatment. For example, those who received payment for use after Period 1 may have been somewhat more aware of the monitors than those in other treatments, because of the incentive. We believe such effects are limited, however, because respondents were treated equally over a reasonably long timeframe with the very small monitors (1.7 $\mathrm{cm}$ in diameter); it is therefore likely that after a short time, users would ignore the device. ${ }^{9}$

We define a cooking event as occurring if the temperature exceeded 40 degrees Celsius. We choose 40 degrees as our cutoff, because it is unlikely to yield false positives, but is not overly conservative. In our research sites, which are in highland areas, the maximum ambient temperature

\footnotetext{
${ }^{9}$ A subset of 108 households participated in three controlled cooking tests that are not part of this study, but are discussed in Gebreegziabher et al. (2018). In our regression models, we control for participation in this activity.
} 
measured using thermometers in respondents' homes was 35 degrees Celsius. We also conduct robustness checks with 45 and 60 degree Celsius cutoff points, which only strengthen our findings.

To measure the frequency of use during a monitoring period, we use signal processing and analysis (O'Haver 1997), which counts the number of contiguous ten-minute logging period blocks the stove surface temperature exceeds the critical value; whether it takes a household 45 minutes or two hours for a particular injera baking event, each event therefore counts as one cooking period. To allow for the possibility that in some weeks the Mirt stove may be used more often than in others, we do not further restrict this measure of usage. It is therefore possible that in a particular week the Mirt stove may not be used at all or could be used several times. The average stove use in a monitoring period is the number of measured cooking events divided by the total days (expressed per week) temperature was measured.

Regular cooking of injera is easily defined compared with other foods (e.g., coffee, stews or breads) and is at least twice per week. To exploit this feature of Ethiopian cooking behavior and focus on true adoption rather than more sporadic, irregular use, which is less meaningful, we mainly examine the effect of our treatments on whether households use the Mirt stove at least twice per week. Such an estimation strategy also helps mitigate any outlier effects. As a robustness check, we analyze cooking frequency as a continuous variable and find no major changes.

The traditional cooking technology in most of Ethiopia and all of our study sites is made from three large stones arranged as a tripod, which is difficult to reliably monitor using SUMs. We therefore imperfectly infer rebound effects, but we note that over $90 \%$ of households report using three-stones in addition to their Mirt stove. This finding is not surprising as Mirt is highly 
specialized for injera baking. ${ }^{10}$ As we are analyzing stove use rather than fuelwood savings, and because any rebound effects apply equally across treatments, rebound effects are of limited relevance. We nevertheless acknowledge that Mirt reduces the cost of cooking in terms of wood use, possibly causing cooks to cook more frequently or to be less attentive while cooking.

\subsection{Sampling Strategy}

The sample villages are randomly selected from a 110 kebele $^{l 1}$ random sample selected in 2012 by the Ethiopian Development Research Institute, from which forestry and other communitylevel data were collected. Information from these study sites was used to test randomization. From the 110 sites, we remove 15 that were covered during our pilot survey. We also remove 14 villages, because three-stone tripods are not used or injera is not typically cooked.

From the remaining 81 villages, we select 36 at random using proportionate random sampling stratified by regional state (Amhara, Oromia and Southern Nations Nationalities and Peoples $[\mathrm{SNNP}]$ ), with the weight of each state determined by its forest area. Forest area is used, because most fuelwood for cooking comes from forests. This measure is also positively correlated with population and land area. Based on this criterion, $20 \%$ of the study sites are from Amhara, $50 \%$ from Oromia and 30\% from SNNP regional states. The selection of villages within each regional state was done using simple random sampling. All sites have formal or informal forest user groups, none of which have legal status.

\footnotetext{
${ }^{10}$ Stoves made from three large stones are easy to move and the fire is difficult to contain, potentially dislodging or overheating SUMs. With its approximately $50 \mathrm{~cm}$ main burner, the Mirt stove cannot accommodate normal pots, making it virtually impossible to shift it to other uses (a potential rebound effect). In contrast to the traditional three-stone stove, the Mirt stove has the capacity to cook with waste gases before they are vented, and over $80 \%$ say they use the second burner for cooking stews and coffee. This feature offers additional efficiencies that likely reduce the need to simultaneously cook on two stoves.

${ }^{11}$ Kebele translates as peasant association and is made up of several villages. It is the smallest jurisdiction in Ethiopia. We have only one randomly selected village per kebele and therefore we use village and kebele interchangeably.
} 
We obtained the official roster of households for each of the 36 village sites from local kebele administrations and from each village 14 households were randomly selected. A total of 360 households (10 from each site) was randomly selected to receive the Mirt stove, with 120 households receiving each monetary treatment. Respondents are adults who make substantive decisions in households and were typically self-identified household heads. If decision makers were not at home when enumerators arrived, respondents were either called home by others or enumerators came back later. Respondents were told by the enumerators that they were chosen randomly to receive a stove under the same terms as others in their village and would also be asked to participate in a baseline survey. The questionnaire included information about the household and the respondent, who was expected to have influence regarding the frequency of Mirt stove use.

Enumerators gave respondents full information on stove features, SUMs and details of the treatment applied to the village. Fieldworkers informed respondents that stove use was not required to receive a stove, but that Mirt was expected to reduce fuelwood consumption and they were encouraged to use them. Respondents were asked for their formal oral consent and all agreed to participate. There was therefore $100 \%$ take-up, likely because of the positive reputation of Mirt, which are typically produced and sold by trained private producers. If there had been refusals, the strategy was to choose randomly from the remaining households in the village. ${ }^{12}$ There was no attrition during the study period.

\footnotetext{
${ }^{12}$ Sample households on average spend significant time collecting fuelwood to be used for cooking. Typically, between one and four household members collect fuelwood an average of three times per week, with each collection trip on requiring approximately four hours. We acknowledge that around the world $100 \%$ uptake is rare, but in SubSaharan Africa, complete initial acceptance is not unheard of. Though monetary treatments differed somewhat from those we use, in Senegal, for example, Bensch and Peters (2015) found that the ICS offered was accepted by all households. Rosa et al. (2014) and Thomas et al. (2013) also have universal initial uptake of freely-distributed modified rocket stoves in Rwanda.
} 
The fieldwork was conducted by five supervisors with significant field experience and an average of four enumerators per supervisor in all four periods of the study. Household representatives came to a centralized location, such as a school or kebele office, to receive their stoves. Villagers then took the six concrete stove pieces and the clay cooking plate (approximately $50 \mathrm{~cm}$ in diameter) called mitad back to their homes (Appendix B). The following day, enumerators came to install the stove in either the main home (36\%) or a separate kitchen $(64 \%)$ by mudding together the six concrete pieces. They also gave cooks training on how to use the stove and the SUM device was installed on the stove using heat-resistant tape.

Enumerators initiated SUM devices and set them to record the surface temperatures of the stoves every ten minutes. We monitored Mirt stove use June-August, 2013 (Period 1); AugustOctober, 2013 (Period 2); March-May 2014 (Period 3) and May-July 2014 (Period 4). No respondents sold or transferred their stoves during any of the periods of the study.

\section{Results}

\subsection{Descriptive statistics}

To contrast short-run and longer-run use and evaluate sustained use of Mirt, we mainly emphasize results from the first (Period 1) and last periods (Period 4), which are approximately 12 months apart. There are seasonal variations in usage and comparing two periods one year apart helps control for these variations. We also present results that include Periods 2 and 3 and show that results do not change and only become more precise when all periods are included.

We check balance across treatments using 11 village-level metrics that are potentially germane to villager decisions about whether to regularly use a new fuelwood saving technology. These variables include average altitude and rainfall, measures of population size, participation in 
forest user groups and changes in forest biomass over time. Only for average annual rainfall can we reject at the $5 \%$ level that treatments are from the same distribution (Appendix C).

Table 1 presents summary statistics for households participating in the field experiment. All variables except baseline measured stove usage come from our household survey and are used as controls in all empirical models; we therefore adjust for systematic differences across households by including these controls. ${ }^{13}$

\section{Table 1 Here}

During each monitoring period, the SUM devices recorded data for between 37 and 56 days. The median recording period was 49 days. Appendix $\mathrm{C}$ presents information on valid observations by period and treatment. In the first and last periods (Periods 1 and 4), which we mainly focus on in our analyses, a maximum of 360 households $(120 * 3)$ could have valid observations. Because of SUM failures, we obtain monitoring data from 300 households in the first period and 301 households in the last period. SUM failures are mainly due to incompletely controlled flames, causing temperature tolerances to be exceeded. An alternative approach to reduce the effects of SUM failures would have been to make much more frequent visits. We considered this an inferior option, however, because during more frequent visits field staff may have unconsciously affected stove use behavior.

We investigate SUM failures and find that most households experience no failures during Periods 1 and 4, which are of primary interest, only 3.9\% had failures in both periods and valid observations are very similar in the two periods. As shown in Appendix C, failures are not peculiar to particular treatments, but differ by periods. We estimate the determinants of SUM failures and

\footnotetext{
${ }^{13}$ For five variables (respondent gender, number of livestock, average number of injera baked, use of Mirt stove for purposes other than injera baking and whether pure teff flour is used to make injera) we can reject that variables come from the same distribution ( $\mathrm{p}<0.05)$. We adjust for these and all variables in Table 1 in all models.
} 
find that failures show no systematic variation with the variables in Table 1 or treatments in either Periods 1 or 4 . Households who used their stoves more frequently in period 3 (the highest average usage period) are more likely to have experienced a SUMs failure $(p=0.04)$. Higher usage in other periods does not affect failures.

\subsection{Stove Usage}

Table 2 presents average Mirt stove usage per week across the four periods by treatment. On average in the pooled sample, and for most periods and treatments, Mirt stoves were used approximately twice per week, suggesting that households typically use the Mirt stove with a frequency consistent with standard injera cooking patterns in areas without refrigeration. Respondents randomized into Incentive Treatment on average were somewhat more likely to regularly use their stoves in Period 1 than those randomly assigned to other treatments. We do not find that usage clusters at the minimum to receive the incentive and we do not find that average stove use decreases after the incentive is withdrawn.

Our finding of regular usage is similar to other African stove adoption literature (e.g., Bensch and Peters, 2015), but is in contrast to the findings of Hanna et al. (2016) for India. We find that in the pooled sample Free Treatment resulted in the highest average stove use of 2.52 times per week, followed by Incentive Treatment. Regular use on average across treatments is notable and indicates that households generally seem to have adopted the technology; this important finding speaks to the potential appropriateness of the Mirt stove in Ethiopia.

Period 4 average usage is in all cases greater than in Period 1 and in Period 3 average usage is also greater than Period $1 .{ }^{14}$ This finding of increasing average use over time probably largely

\footnotetext{
${ }^{14}$ Period 3 has the highest average use across all treatments. Ambient temperatures are warmest during March to May. Households therefore need to cook more often to avoid spoilage.
} 
reflects learning to use the stove more effectively. As reported in a related paper (Gebreegziabher et al. 2018), which utilizes a sub-sample that participated in controlled cooking tests, average time to cook a standardized batch of injera fell substantially over this period.

\section{Table 2 Here}

We now turn our attention to estimating the effects of different monetary incentives on regular use, irregular use and dis-adoption. We first categorize average usage into three groups: (i) at least twice per week, which means households are regular users of the stove, (ii) used, but less than twice per week and (iii) non-use over each approximately six-week monitoring period. In Figure 1, we show usage intensity by treatment in Periods 1 and 4 . In general, over the one-year timeframe we observe a slight increase in the proportion of households using the stove more than twice per week (from $42 \%$ to $51 \%$ ) and of non-users (from $6 \%$ to $11 \%$ ). In Period 1 , we find the highest proportion of regular users in Incentive Treatment (45\%), while in Period 4 it is in Free Treatment (56\%). Using a $\chi^{2}$ test, at the $5 \%$ significance level we can neither reject that the distributions are different between periods for each treatment separately nor that the distribution of usage is different between treatments for each period separately. ${ }^{15}$

\section{Figure 1 Here}

In Appendix $\mathrm{C}$ we present detailed results by Treatment. We find that while in Period 1 regular usage in the Incentive Treatment was above the other two treatments ( $45 \%$ versus $38 \%)$, with no non-users (versus $9 \%-11 \%$ for other two treatments), by Period four $11.1 \%$ Incentive Treatment respondents had stopped using their stoves. At 56\%, Free Treatment in Period 4 has the highest portion of regular users (versus $47 \%$ for Pay Treatment and $51 \%$ for Incentive

\footnotetext{
${ }^{15}$ During the period of analysis, there was no significant damage to stoves. At the end of Period 4, all Mirt stoves could be used. As a robustness check, in Appendix C we include results only for households without SUM failures in either Periods 1 or 4 . We find results that are very similar to those presented in Figure 1.
} 
Treatment) and lower levels of dis-adoption than Pay Treatment, but not Incentive Treatment. Compared with the other monetary incentives, Incentive Treatment is found to generate a bit more short-run adoption, but Free Treatment appears to be most consistent with longer-run regular use.

\subsection{Explaining Stove Regular Use}

Table 3 presents results of random effects probit regressions to explain regular use of the Mirt stove in Periods 1 and 4 using a difference-in-difference specification. Table 4 has the same models using observations from all four periods and shows that results are virtually identical, though increased degrees-of-freedom in Table 4 provide more precise estimates. Random effects account for time invariant household-level unobservables and results are virtually the same in our pooled probit models, which are included in Appendix $\mathrm{C}$ along with random effects probit results that include all controls; as they are not the main focus, the controls are only briefly discussed.

Regressors include treatments interacted with time period, as well as the socioeconomic and cooking controls presented in Table 1. These controls are included, because they could influence the frequency of Mirt stove use regardless of treatments, household unobservables or time trends. We also include a dummy for whether villages had group training and Q\&A, as well as individual training. We cluster errors at the village level, which is the highest level of aggregation relevant to our treatments (Cameron et al. 2011). Free Treatment in Period 4 is the omitted category, which means we compare treatments with the longer-run effect of pure free distribution. Thus, a positive coefficient for a treatment in a specific period means that this treatment in that period is more likely to result in regular use than Free Treatment in Period 4.

We include a number of robustness checks, including analysis of households with no SUM failures to be sure that the distribution of SUM failures does not affect our results. These results are presented in column 3 of Tables 3 and 4; we find that households without SUM failures show very similar results. In Appendix $\mathrm{C}$ we include several additional checks. These include OLS 
results with numbers of cooking periods rather than categories as the independent variable and find no differences from the estimates presented below. We also present models with cooking events defined as 45 and 60 degrees Celsius and find either very similar results or that more stringent definitions of cooking events reinforce our findings. We estimate wild bootstrapped (1000 replications) probit models, utilizing the score bootstrapping algorithm of Kline and Santos (2012) implemented via the STATA boottest postestimation command. This method is particularly suited to estimating standard errors with relatively few clusters (our 36 clusters is above the suggested cutoff). These models give less precise estimates than in Tables 3 and 4.

As shown in Table 3, all treatments show negative, and in some cases significant coefficients, meaning that they are equally or less likely to promote regular use than Free Treatment in Period 4. The significant negative coefficient for Free Treatment Period 1 (P value $=0.04$ ) is economically significant and we find that between Periods 1 and 4, the estimated probability of regular usage under Free Treatment increases by $51 \%$ (overall sample) to $79 \%$ (subsample with no SUMs failures), suggesting free distribution promotes increasing regular usage over time. ${ }^{16}$ The coefficient estimate for Pay Treatment Period 1 is also negative, but significant only at the $10 \%$ level. Results are similar for the subsample without SUM failures. We acknowledge that lack of statistical precision could be the result of our sample size, so insignificant results should not necessarily be interpreted as no effect.

\section{Table 3 Here}

Table 4 presents results for all periods and we find they are virtually identical to those in Table 3, but with increased precision. In the full sample, coefficient estimates for Free Treatment

\footnotetext{
${ }^{16}$ Actual change in regular usage was from $42 \%$ to $56 \%$, which is less than the estimated percentage. The difference is likely due to including socioeconomic and cooking characteristic controls.
} 
and Pay Treatment in Period 1 are again negative and large in magnitude, but with data from all four periods included, both are significant at the 5\% level; households who were randomized into Free Treatment are estimated to have a $59 \%$ to $88 \%$ greater chance of regular use in Period 4 than in Period 1. We also see that Pay Treatment Period 2 has less regular Mirt stove use than Free Treatment Period 4. In both models, except for Free Treatment in Period 3, estimated coefficients are negative and magnitudes are similar to those in Table 3.

\section{Table 4 Here}

A number of control variables offer insights that should be mentioned. In all our specifications the $36 \%$ of Mirt stoves installed in main houses rather than in separate indoor kitchens are regularly used about $79 \%$ less than the average $(\mathrm{P}<0.001)$. This suggests that users prefer to cook injera outside the main home. We also find that larger households, those that cook more injera during each baking session and those who cook foods other than injera on the stove are more likely to regularly use Mirt stoves; the Mirt stove may therefore offer scale economies.

We use results from Model 1 in Table 4 and compare the effects of treatments on regular usage by period. We conduct pairwise likelihood ratio tests of whether estimated parameters in Table 4 are equal across treatments, but within periods. The only statistically significant difference is that Incentive Treatment in Period 1 has statistically higher usage than Pay Treatment, which is likely due to the monetary incentive. We do not observe sunk cost effects, as usage is statistically the same for Pay and Free Treatment households in all periods, and acknowledge that we could potentially observe sunk cost effects if the Pay Treatment subsidy was reduced. We also find no evidence that Incentive Treatment incentivizes usage behaviors that are sufficiently persistent to cause it to better promote Period 4 regular use than the other two treatments. That it is not less 
effective than Pay Treatment also suggests, however, that incentives do not crowd out intrinsic motivations based, for example, on performance of the Mirt stove.

We also use the results from Table 4 to analyze decreasing, persistent and increasing regular use of the improved stove. We find that both Pay Treatment and Free Treatment on average promote increased regular use over time, which is in line with our descriptive results. Pay Treatment has the biggest increase in regular usage, but Period 4 average usage is much higher for Free Treatment (2.73 versus 2.29 times per week or $\approx 20 \%$ ); in Tables 3 and 4, estimated Period 4 Pay Treatment coefficients are negative, but not statistically significant. The Period 1 average usage for Pay Treatment was the lowest by a wide margin and statistically less than Incentive Treatment $(\mathrm{p} \approx 0.09)$. Free Treatment generates the highest usage in Period 4 and promotes increased regular usage over time. These test results are provided in Appendix C.

As a robustness check, we re-run Model 1 in Table 4 with 45 degree C and 60 degree C definitions of cooking events. As shown in Appendix C, reducing the chance of mistakenly identifying cooking events when none occurred only serves to increase the statistical precision of our estimates. All treatment coefficient estimates are negative.

\subsection{Summary of Findings and External Validity}

A large proportion of the human population in low-income countries, particularly in SubSaharan Africa, still uses biomass fuels for cooking. ICS, such as the Mirt stove, can contribute to reduced use of fuelwood, possibly resulting in positive effects on forests, the climate and human welfare if stoves are effective and regularly used. The objective of this paper is to use a field experiment to evaluate the effect of monetary treatments on short and longer-run ICS usage intensity. The monetary treatments examined in this paper - Pay, Free and Incentive - are common to many cookstove programs and closely resemble real-world treatments. These treatments are 
also salient in the health technology literature, but to-date somewhat less so in the ICS literature, a gap our paper seeks to help fill.

Our research has three main findings. First, based on measured free-will usage and informed by our analytical model, the Mirt stove appears to deliver net benefits that are sufficient for cooks to use it regularly. Our second main finding is that making people pay a price for the Mirt stove or offering them a usage incentive does not increase use frequency vis-à-vis free distribution, especially in the longer-run over a period of approximately one year. These results are in accord with our simple analytical model, as well as the findings of Ashraf et al. (2010), which suggest that sunk costs should have no effect on use.

Though offering first period incentives to use the Mirt stove perhaps spurs regular use during the first monitoring period, average use after approximately one year is a bit lower than under Free Treatment. In the pooled sample and in three of four periods, Free Treatment average usage is indeed greater than the other two treatments. Finally, in contrast with Incentive Treatment, Free Treatment and Pay Treatment promote increasing use over time and we estimate the effects to be highly economically significant. Free Treatment in the longer-run promotes regular usage better than other treatments, but results are sometimes not statistically significant. We may simply be unable to detect all effects of our treatments.

How externally valid are our findings? Ethiopia is part of a suite of low-income countries with institutional constraints, such as poorly functioning labor, credit and savings markets that have important influences on affordability. Our findings on monetary treatments may therefore be externally valid in rural areas of other low-income countries if, as appears to be the case for the Mirt stove, improved biomass cooking stoves are appropriate for users. This means that stoves must be consistent with cooking needs (e.g., not be too inconvenient to use), should fulfill 
expectations to reduce fuelwood consumption and must be sufficiently durable so they can be regularly used for extended periods. Studies that have noted low usage intensity have typically identified one or more of these characteristics that were not fulfilled.

We did not vary incentives and cost treatments and therefore can only speculate on the effects of levels other than those we provided. Such research would be an obvious extension. In particular, while with our Pay Treatment all potential recipients accepted the stove, at dramatically higher prices screening effects are to be expected.

A combination of appealing features of the Mirt stove, low cost, durability during the first year and fuelwood savings with no increase in cooking time (Gebreegziabher et al. 2018), appears to have resulted in a technology that is on average regularly used and avoids important problems, such as abandonment and disuse, that have bedeviled other improved stove programs, notably in South Asia, where cooking patterns can be highly diverse. ${ }^{17}$ That the Mirt stove cooks such a specialized food certainly should be cause for pause before generalizing findings to very different contexts. It is also significant that cooks do not typically bake injera every day, while even in other Sub-Saharan countries the main starch is cooked daily. Finally, the Mirt stove is designed primarily to reduce fuelwood consumption. Survey evidence from our sample suggests that many households experience significant firewood scarcity. Our results on usage may therefore not transfer well to areas where firewood scarcity is less important.

\section{Conclusions and Policy Implications}

Appropriate improved stoves that support well-defined uses may have opportunities for success that are similar to the Mirt stove. We find that providing Mirt stoves free-of-charge is at

\footnotetext{
${ }^{17}$ All Mirt stoves remained in place during the first year. There was no abandonment and no breakage that precluded use. Zero usage was no more than $11 \%$ in Period 4.
} 
least as effective as other monetary treatments in terms of encouraging high levels of regular usage and is the most effective treatment to promote high and increasing levels of longer-run use. Those wishing to promote Mirt stoves and perhaps other improved biomass cookstoves with similar characteristics may therefore not need to excessively worry that giving stoves away will adversely affect usage. Though free distribution certainly has budgetary consequences, this finding is encouraging, because Mirt and other ICS promoted in Sub-Saharan Africa cost relatively little (e.g. $\$ 12.00)$; free distribution may therefore be a programmatic possibility, particularly when carbon finance can reduce costs (Levine et al. 2018), and offers the advantage of increasing real incomes for often poor households. Free distribution also avoids the monitoring associated with usage incentives. Indeed, we find such incentives are unnecessary to promote longer-run regular use.

We are now in a period of intensive evaluation of fuel-efficient biomass stoves in many areas of the developing world. It is therefore critical to understand what factors drive regular use and we strongly suggest that, when possible, stove programs should be implemented in conjunction with field experiments. It is our hope that by better understanding what promotes intensive use over the time periods we have investigated, ICS can more effectively fulfill their potential to improve the welfare of those dependent on biomass fuels.

\section{References}

Alcott, H. and T. Rogers. 2014. "The Short-Run and Long-Run Effects of Behavioral Interventions: Experimental Evidence form Energy Conservation.” American Economic Review 104: 3003-3037.

Alem, Y, S. Hassan, G. Köhlin. 2014. "The Dynamics of Electric Cookstove Adoption: Panel Data Evidence from Ethiopia." Resource and Energy Economics 43: 153-171.

Amacher, G., L. Ersado, D. L. Grebner and W. F. Hyde. 2004. "Disease, Microdams and Natural Resources in Tigray, Ethiopia: Impacts on Productivity and Labour Supplies." Journal of Development Studies 40: 122-145.

Ashraf, N., J. Berry and J. Shapiro. 2010. "Can higher prices stimulate product use? Evidence from a field experiment in Zambia." American Economic Review 100: 2383-2413. 
Bailis, R. 2018. "Energy Transitions in India: LPG Adoption in South India." Presentation at the Third Annual Sustainable Energy Transitions Initiative Conference, Duke University May $16,2018$.

Bailis, R, R. Drigo, A. Ghilardi, O. Masera. 2015. "The Carbon Footprint of Traditional Woodfuels." Nature Climate Change 5: 266- 272.

Barnes, D, K. Openshaw, K. Smith and R. van der Plas. 1993. "The Design and Diffusion of Improved Cooking Stoves.” World Bank Research Observer 8: 119-141.

Beltramo, T, G. Blalock, D. Levine and A. Simons. 2015. "The Effect of Marketing Messages and Payment over Time on Willingness to Pay for Fuel-Efficient Cookstoves," Journal of Economic Behavior and Organization 118: 333-345

Beltramo, T. and D.I. Levine. 2013. "The Effect of Solar Ovens on Fuel Use, Emissions and Health: Results from a Randomised Controlled Trial." Journal of Development Effectiveness 5: 178-207.

Bensch, G. and Peters, J. 2017. "One-Off Subsidies and Long-Run Adoption. Experimental Evidence on Improved Cooking Stoves in Senegal." Environment for Development Discussion Paper 17-17.

Bensch, G. and J. Peters. 2015. "The Intensive Margin of Technology Adoption - Experimental Evidence on Improved Cooking Stoves in Rural Senegal. Journal of Health Economics 42: 44-63.

Bensch, G. and J. Peters. 2013. "Alleviating Deforestation Pressures? Impacts of Improved Stove Dissemination on Charcoal Consumption in Urban Senegal." Land Economics 89: 676698.

Bensch, G, M. Grimm and J. Peters. 2015. "Why do Households Forego High Returns from Technology Adoption? Evidence from Improved Cooking Stoves in Burkina Faso. Journal of Economic Behavior and Organization 116: 187 - 205.

Beyene, A. D., R. A. Bluffstone, Z. Gebreegziabher, P. Martinsson, A. Mekonnen and F. Vieider, "The Improved Biomass Stove Saves Wood, but How Often do People Use it?" Policy Research Working Paper 7297, June 2015. The World Bank, Washington, DC.

Bizzari, M. 2010. Safe Access to Firewood and Alternative Energy in Ethiopia: An Appraisal Report. Prepared for the World Food Program. http://www.genderconsult.org/uploads/publications/doc/SAFE_Ethiopia_Appraisal_Repo rt Final Draft 2.pdf Accessed May 12, 2015.

Bluffstone, R. 1995. "The Effect of Labor Markets on Deforestation in Developing Countries Under Open Access: An Example from Rural Nepal." Journal of Environmental Economics and Management 29: 42-63.

Bond, T., Doherty, S., Fahey, D., Forster, P., Bernsten, T., DeAngelo, B., Flanner, M., Ghan, S., Karcher, B., Koch, D., Kinne, S., Kondo, Y., Quinn, P., Arofim, M., Schultz, M., Schulz, M., Venkataraman, C., Zhang, H., Zhang, S., Bellouin, N., Guttikunda, S., Hopke, P., Jacobsen, M., Kaiser, J., Klimont, Z., Lohmann, U., Schwarz, J., Shindell, D., Storelvmo, T., Warren, S. and Zender, C. 2013. "Bounding the Role of Black Carbon in the Climate System: A Scientific Assessment." Journal of Geophysical Research Atmospheres 118: 5380-5552.

Brooks, N. A, V. Bhojvaid, M.A. Jeuland, J.J. Lewis, O. Patange, S.K. Pattanayak. 2016. "How much do Alternative Cookstoves Reduce Biomass Fuel Use? Evidence from North India." Resource and Energy Economics 43: 153-171. 
Cameron, C, J. Gelbach and D. Miller. 2011. "Robust Inference with Multiway Clustering." Journal of Business and Economic Statistics 29 (2): 238-249.

Cameron, A.C., J.B. Gelbach, and D.L. Miller. 2008. "Bootstrap-Based Improvements for Inference with Clustered Errors." The Review of Economics and Statistics 90: 414-27.

Charness, G. and U. Gneezy. 2009. "Incentives to Exercise." Econometrica 77: 909-931

Chassang, S, G. Padro and E. Snowberg. 2012. "Selective Trials: A Principal-Agent Approach to Randomized Controlled Experiments." American Economic Review 102: 1279 - 1309.

Cohen, J., and P. Dupas. 2010. "Free distribution or cost-sharing? Evidence from a randomized malaria prevention experiment." Quarterly Journal of Economics 124: 1-45.

Cooke, P., G. Köhlin, W. F. Hyde. 2008. "Fuelwood, Forests and Community Management Evidence from Household Studies." Environment and Development Economics 13: 103135.

Dresen, Elisabeth, Ben DeVries, Martin Herold, Louis Verchot and Robert Müller. 2014.

"Fuelwood Savings and Carbon Emission Reductions by the Use of Improved Cooking Stoves in an Afromontane Forest, Ethiopia." Land 3: 1137-1157; doi:10.3390/land3031137

DFID (Department for International Development). Undated. "Dynamics of Urban Change," available at $\quad$ http://www.ucl.ac.uk/dpuprojects/drivers_urb_change/VIDEOS/what_s_cooking.htm, accessed May 29, 2018.

Dupas, P. 2014. "Short-Run Subsidies and Long-run Adoption of New Health Products: Evidence from a Field Experiment." Econometrica 82: 197-228.

FDRE, 2011. Ethiopia's Climate-Resilient Green Economy: Green Economy Strategy.

FDRE 2015. Ethiopia's Climate-Resilient Green Economy Climate Resilience Strategy: Water and Energy. Ministry of Water, Irrigation and Energy, Federal Democratic Republic of Ethiopia (FDRE).

Frey, E. and T. Rogers. 2014. "Persistence: How Treatment Effects Persist After Interventions Stop." Policy Insights from the Behavioral and Brain Sciences 1:172-179

Gebreegziabher, Z. and G. C. van Kooten, 2013. "Does Community and Household Tree Planting Imply Increased Use of Wood for Fuel? Evidence from Ethiopia." Forest Policy and Economics 34:30-40.

Gebreegziabher, Z, A. Beyene, M. Toman, R. Bluffstone, S. Dissanayake, P. Martinsson. 2018. "Fuel Savings, User Satisfaction and Demand for Improved Biomass Cookstoves: Evidence from a Controlled Cooking Test Trial in Ethiopia." Resource and Energy Economics 52: 173-185.

Gil, J. 1987. "Improved Stoves in Developing Countries: a Critique." Energy Policy April: 135144.

GIZ. 2011. Mirt Stove Ethiopia Accessed 1 November 2015 at

http://cdm.unfccc.int/filestorage//p/LRDOC4GHWKQI80BUYVZA2J96ETF513/Additi onal $\% 20$ information $\% 3 \mathrm{~A} \% 20 \mathrm{Mirt} \% 20$ Stove.pdf?t=N1Z8bnoyNzllfDAYSIDC5dM6 B7 4OWk4OQ0A

Grieshop, A. P., P. J. D. Marshall and M. Kandlikar. 2011. "Health and Climate Benefits of Cookstove Replacement Options."'Energy Policy 39: 7530-7542.

Hanna, R, E. Duflo and M. Greenstone. 2016. "Up in Smoke: the Influence of Household Behavior on the Long-Run Impact of Improved Cooking Stoves." American Economic Journal: Economic Policy 8(1): 80-114. 
IEA 2017. World Energy Access Outlook 2017: From Poverty to Prosperity. World Energy Outlook Special Report. International Energy Agency. Paris: IEA.

Jeuland, M. A, V. Bhojvaid, A. Kar, O. Patange, S. K. Pattanayak, N. Ramanathan, I. H. Rehman, J.S. Tan Soo and V. Ramanathan. 2015a. "Preferences for Improved Cook Stoves: Evidence from Rural Villages in North India.” Energy Economics 52: 287-298.

Jeuland, M. A, Pattanayak, S. and Bluffstone, R. 2015b. "The Economics of Household Indoor Air Pollution." Annual Review of Environmental and Resource Economics 7(1), 81-108.

Jeuland, M. A. and S. Pattanayak. 2012. "Benefits and Costs of Improved Cookstoves: Assessing the Implications of Variability in Health, Forest and Climate Impacts."PloS one, 7, e30338.

Johnson, M, R. Edwards, A. Ghilardi, V. Berrueta, D. Gillen, C. A. Frenk and O. Masera. 2009. "Quantification of Carbon Savings from Improved Biomass Cookstove Projects. Environmental Science and Technology 43: 2456-2462.

Kindu Trust. "Mirt Stove Distribution Project." https://kindutrust.org/projects/mirt-stovedistribution-project/

Kline, P., and Santos, A. 2012. "A Score Based Approach to Wild Bootstrap Inference." Journal of Econometric Methods 1: 23-41.

Levine, D.I., Beltramo, T., Blalock, G., Cotterman, C. and Simons, A. 2018. "What Impedes Efficient Adoption of Products? Evidence from Randomized Sales Offers for FuelEfficient Cookstoves in Uganda." Journal of the European Economic Association, forthcoming.

Lewis, J. and S. Pattanayak. 2012. "Who Adopts Improved Fuels and Cookstoves? A Systematic Review. Environmental Health Perspectives 120: 637-644.

Lim, S, T. Vos,A. D. Flaxman., G. Danaei, K. Shibuya, H. Adair-Rohani, . A. Almazroa, M. Amann, H. R. Anderson, and K. G. Andrews. 2013. "A Comparative Risk Assessment of Burden of Disease and Injury Attributable to 67 Risk Factors and Risk Factor Clusters in 21 Regions, 1990-2010: a Systematic Analysis for the Global Burden of Disease Study 2010.”The Lancet 380: 2224-2260.

Martin, W J., R. I. Glass, J. M. Balbus, and F. S. Collins. 2011. “A Major Environmental Cause of Death." Science 344: 180-181.

Megen Power Ltd. 2008. Final Report: Impact Assessment of Mirt Improved Biomass Injera Stoves [sic] Commercialization in Tigray, Amhara and Oromiya National Regional States, Submitted to the MoARD/GTZ SUN Energy Programme, Addis Ababa

Mobarak, A. M, P. Dwivedi, R. Bailis, L. Hildemann, and G. Miller, 2012. "Low Demand for Nontraditional Cookstove Technologies," Proceedings of the National Academies of Sciences. 109: 10815-10820.

Mondal, M. A, E. Bryan, C. Ringler, D. Mekonnen, M. Rosegrant. 2018. "Ethiopian Energy Status and Demand Scenarios: Prospects to Improve Energy Efficiency and Mitigate GHG Emissions" Energy 149: 161-172.

O'Haver, T, 1997. "A Pragmatic Introduction to Signal Processing with applications in scientific measurement: An illustrated essay," Department of Chemistry and Biochemistry, University of Maryland at College Park; http://terpconnect.umd.edu/ toh/spectrum/IntroToSignalProcessing.pdf

Pattanayak, S. K. and A. Pfaff. 2009. "Behavior, Environment, and Health in Developing Countries: Evaluation and Valuation.” Annual Review of Resource Economics 1: 183-217. 
Pattanayak, S. K., M. A. Jeuland, J. Lewis, V. Bhojvaid, N. Brooks, A. Kar, L. Lipinski, L. Morrison, O. Patange, N. Ramanathan, I.H. Rehman, R. Thadani, F. Usmani, M. Vora, V. Ramanathan. 2016. "Cooking up Change in the Himalayas: Experimental Evidence on Cookstove Promotion." Duke Environmental and Energy Economics Working Paper Series EE 16,3 .

Ramanathan, T., N. Ramanathan, J. Mohanty, I H. Rehman, E. Graham and V. Ramanathan. 2016. "Wireless Sensors Linked to Climate Financing for Globally Affordable Clean Cooking." Nature Climate Change 7: $44-47$.

Rosa, G, F. Majorin, S. Boisson, C. Barstow, M. Johnson, M. Kirby, F. Ngabo, E. Thomas, T. Clasen. 2014. "Assessing the Impact of Water Filters and Improved Cook Stoves on Drinking Water Quality and Household Air Pollution: A Randomised Controlled Trial in Rwanda." PLoS ONE 9(3): e91011. doi:10.1371/journal.pone.0091011

Ruiz-Mercado, I. and O. Masera. 2015. "Patterns of Stove Use in the Context of Fuel-Device Stacking: Rationale and Implications." EcoHealth 12: $42-56$.

Saatchi SS, Harris NL, Brown S, Lefsky M, Mitchard TAE, Salas W, Zutta BR, Buermann W, Lewis SL, Hagen S, Petrova S, White L, Silman M and Morel A. 2011. "Benchmark Map of Forest Carbon Stocks in Tropical Regions across Three Continents." PNAS 108(24): 9899-9904.

Samaddar, S. 2017. "Adoption and Short-term Impacts of Improved Cookstoves in Rural India," Master's Project, Sanford School of Public Policy, Duke University.

Simons, A. M., T. Beltramo, G. Blalock and D. Levine. 2017. "Using Unobtrusive Sensors to Measure and Minimize Hawthorne Effects: Evidence from Cookstoves." Journal of Environmental Economics and Management 86: 68 - 80.

Smith, K. R, H. Frumkin, K. Balakrishnan, C. D. Butler, Z. A. Chafe, I. Fairlie, P. Kinney, T. Kjellstrom, D. L. Mauzerall and T. E. McKone. 2013. "Energy and Human Health."Annual Review of Public Health 34: 159-188.

Tesfay, A. H, M. B. Kahsay, O. J. Nydal. 2014. "Solar Powered Heat Storage for Injera Baking in Ethiopia." Energy Procedia 57: 1603-1612.

Thomas, E., C. Barstow, G. Rosa, F. Majorin and T. Clasen. 2013. "Use of Remotely Reporting Electronic Sensors for Assessing Use of Water Filters and Cookstoves in Rwanda." Environmental Science \& Technology 47: 13602-13610

Usmani, F., J. Steele and M. Jeuland. 2017. "Can Economic Incentives Enhance Adoption and Use of a Household Energy Technology? Evidence from a Pilot Study in Cambodia." Environmental Research Letters 12(3): 035009.

Vieider, F, A. Beyene, R. Bluffstone, S. Dissanayake, Z. Gebreegziabher, P. Martinsson, A. Mekonnen. 2018 "Measuring Risk Preferences in Rural Ethiopia.” Economic Development and Cultural Change 66(3): 417-446.

World Food Program. Undated Website. "Fuel Efficient Stoves for Ethiopia Programme of Activities Non-Technical Summary." https://www.wfp.org/sites/default/files/Non\%20technical $\% 20$ summary $\% 20$ Fuel $\% 20$ Effic ient\%20stoves\%20for\%20Ethiopia\%20PoA.pdf Accessed May 24, 2018.

Wrangham, R.W., J.H. Jones, G. Laden, D. Pilbeam and N.L. Conklin-Brittain. 1999. "The Raw and the Stolen: Cooking and the Ecology of Human Origins." Current Anthropology 40: 567-594. 
Figure 1. Stove Usage Intensity by Treatment for Periods 1 and 4

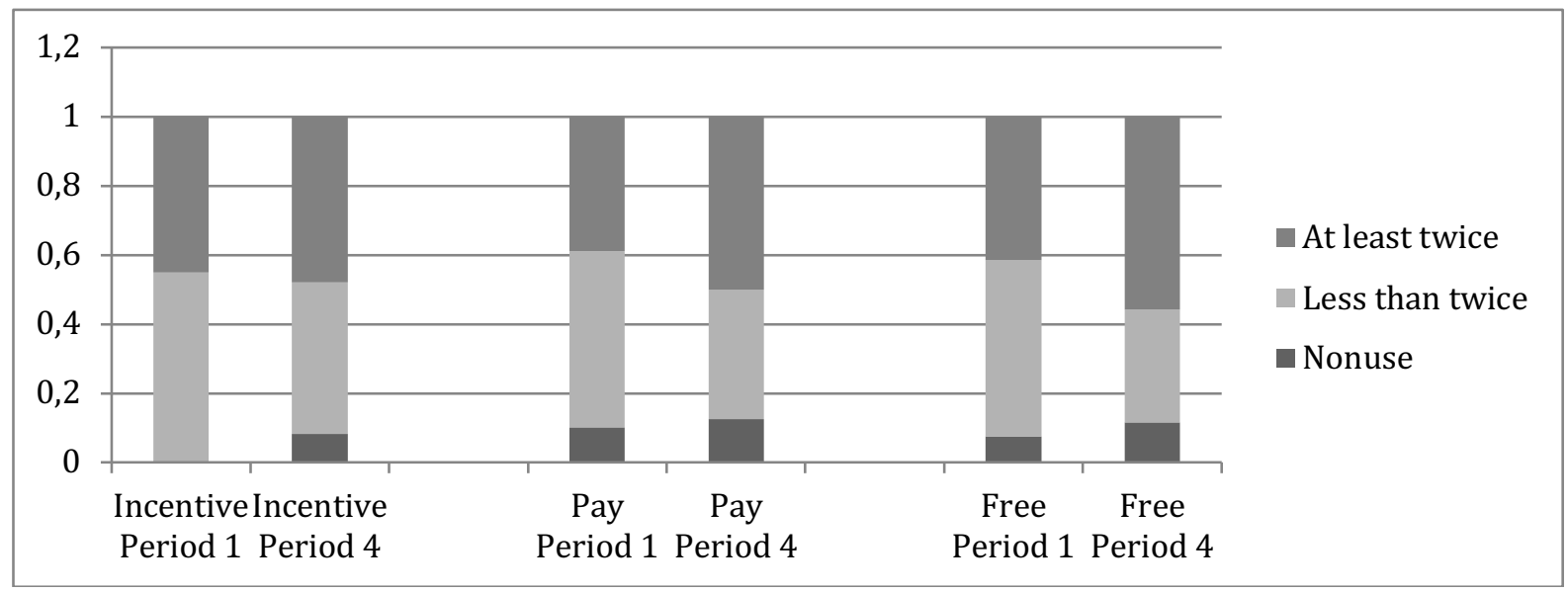

Table 1. Descriptive statistics

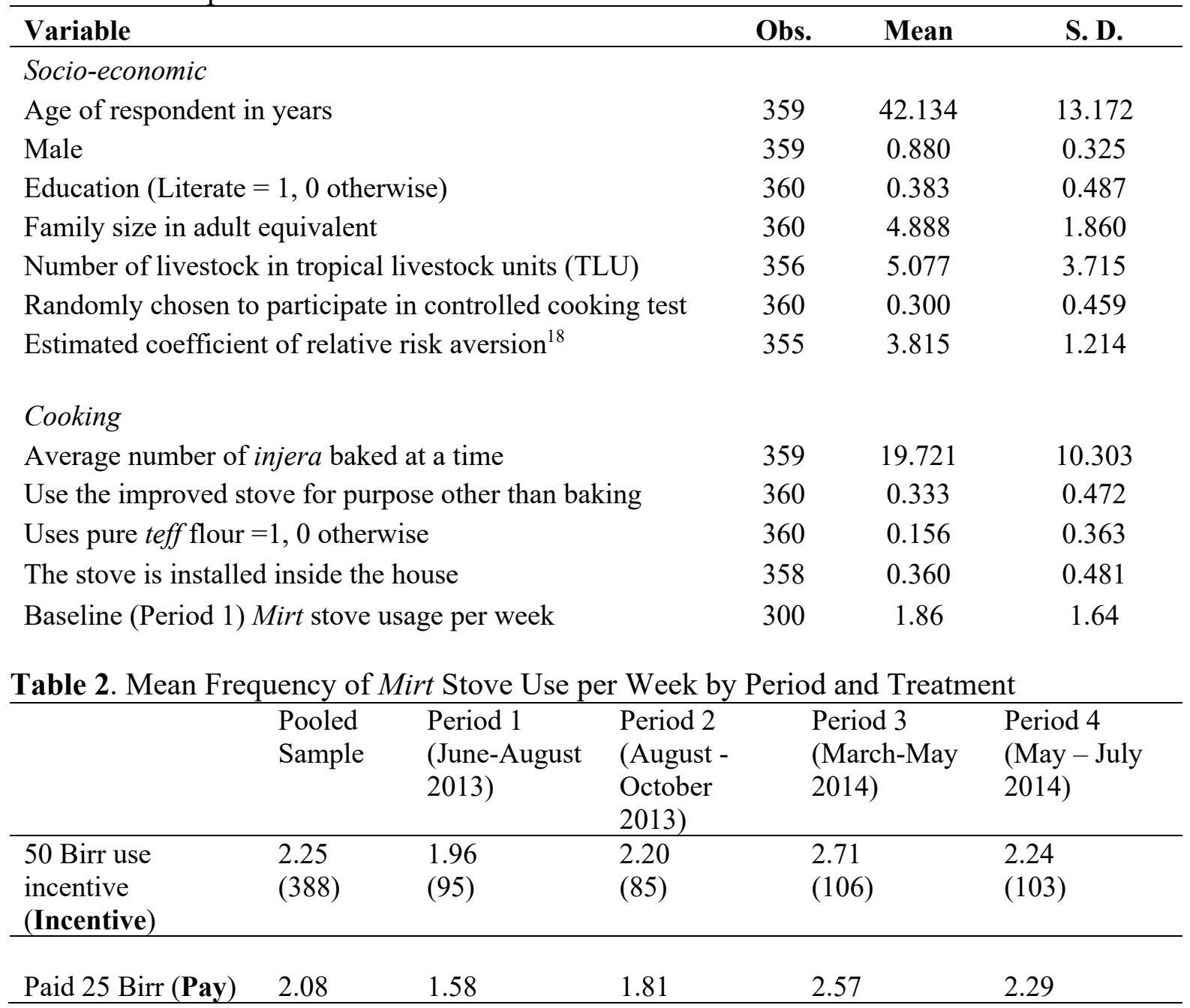

${ }^{18}$ Please see Vieider et al. (2018) for a discussion of the method used to estimate risk aversion. 


\begin{tabular}{llllll}
\hline & $(424)$ & $(102)$ & $(104)$ & $(111)$ & $(107)$ \\
$\begin{array}{l}\text { Received stove for } \\
\text { free (Free) }\end{array}$ & 2.52 & 2.08 & 2.44 & 2.42 & 2.73 \\
$(393$ & $(103)$ & $(98)$ & $(101)$ & $(91)$
\end{tabular}

120 households were randomized into each cell in Table 2. Valid observations in parentheses.

Table 3. Random Effects Probit Regression of Use of Mirt Stove at Least Twice per Week (Marginal Effects) for Periods 1 and 4

\begin{tabular}{lcc}
\hline Variable & Model 1 & Model 2 \\
\hline Incentive Period 1 & All Households & $\begin{array}{l}\text { Households with no SUM } \\
\text { Failure in any Period. }\end{array}$ \\
\hline Incentive Period 4 & $-0.330(0.49)$ & $-0.186(0.56)$ \\
Pay Treatment Period 1 & $-0.153(0.516)$ & $-0.077(0.59)$ \\
Pay Treatment Period 4 & $-1.040(0.62)^{*}$ & $-0.725(062)$ \\
Free Treatment Period 1 & $-0.135(0.54)$ & $-0.050(0.55)$ \\
Socioecon. Characteristics & $-0.514(0.25)^{* *}$ & $-0.792(0.23)^{* * *}$ \\
Cooking Characteristics & YES & YES \\
Group Training Dummy & YES & YES \\
\hline Wald $X^{2}$ (17) (Prob. $\left.>X^{2}\right)$ & YES & YES \\
\hline Ln(sigma ${ }^{2}$ mu) & $43.92(0.00)^{* * *}$ & $36.66(0.00)^{* * *}$ \\
\hline Number of Groups & $0.174(1.42)$ & $0.032(0.47)$ \\
\hline Observations & 334 & 222 \\
\hline
\end{tabular}

Free Treatment Period 4 is the omitted category. In all models we control for the variables presented in Table 1. Robust standard errors clustered at kebele/village level in 36 clusters. ***,**,* indicate significant at the 1\%, 5\% and $10 \%$ levels, respectively. In no model is the group training dummy statistically significant.

Table 4. Random Effects Probit Regression of Use of Mirt Stove at Least Twice per Week (Marginal Effects) All 4 Periods

\begin{tabular}{lcc}
\hline & Model 1 & Model 2 \\
\hline Variable & All Households & $\begin{array}{l}\text { Households with no SUM } \\
\text { Failure in Any Period. }\end{array}$ \\
\hline Incentive Period 1 & $-0.407(0.46)$ & $-0.224(0.55)$ \\
\hline Incentive Period 2 & $-0.158(0.49)$ & $-0.043(0.58)$ \\
\hline Incentive Period 3 & $-0.165(0.48)$ & $0.074(0.55)$ \\
\hline Incentive Period 4 & $-0.23(0.50)$ & $-0.110(0.58)$ \\
Pay Treatment Period 1 & $-1.20(0.51)^{* *}$ & $-0.827(0.56)$ \\
Pay Treatment Period 2 & $-0.936(0.45)^{* *}$ & $-0.646(0.52)$ \\
Pay Treatment Period 3 & $-0.161(0.42)$ & $0.018(0.49)$ \\
Pay Treatment Period 4 & $-0.207(0.43)$ & $-0.095(0.50)$ \\
Free Treatment Period 1 & $-0.59(0.27)^{* *}$ & $-0.888(0.22)^{* * *}$ \\
Free Treatment Period 2 & $-0.012(0.23)$ & $-0.128(0.28)$ \\
Free Treatment Period 3 & $0.281(0.21)$ & $0.20(0.28)$ \\
Socioecon. Characteristics & YES & YES
\end{tabular}




\begin{tabular}{lcc} 
Cooking Characteristics & YES & YES \\
Group Training Dummy & YES & YES \\
\hline Wald $\mathrm{X}^{2}(26)$ & $85.65(0.00)^{* * *}$ & $65.46(0.00)^{* * *}$ \\
\hline Ln $\left(\right.$ sigma $\left.^{2} \mathrm{mu}\right)$ & $0.504()$. & $0.457()$. \\
\hline Number of Groups & 342 & 222 \\
\hline Observations & 1166 & 888
\end{tabular}

Free Treatment Period 4 is the omitted category. In all models we control for the variables presented in Table 1. Robust standard errors clustered at kebele/village level in 36 clusters. convergence. $* * *, * *, *$ indicate significant at the $1 \%, 5 \%$ and $10 \%$ levels, respectively. In no model is the group training dummy statistically significant. 